\title{
RASKOLNIKOV: BÚSQUEDA DE LA AUTOAFIRMACIÓN DESDE LA DESESPERACIÓN
}

\author{
Nathalie Chamorro Nuñez ${ }^{1}$ \\ Universidad Santo Tomás
}

Recibido: febrero 15 de 2005

Aprobado: abril 1 de 2005

\section{Resumen}

En el presente ensayo se busca considerar a Raskolnikov como un ser desesperado desde la óptica de Hegel, al debatirse entre su deseo y la realidad. También se parte de que toda desesperación debe llevar a una acción que brinde la salida a la encrucijada, y se desea dejar en claro que esta salida es el amor como una superación de la misma filosofía hegeliana, al considerar que el individuo puede llegar a un autoconocimiento desde su propia autoafirmación y a la vez es la superación del mismo Raskolnikov dentro de su moral egoísta.

\section{Palabras clave}

Hegel, Dostoievsky, conciencia desgraciada, autoconciencia, autoafirmación

\section{Abstract}

The present assay seeks to consider Raskolnikov as a desperated being from Hegel's point of view, who struggles among his desires and reality. It also starts from the concept that all despair must lead to an action that offers the exit to the cross-roads, and it is wished to leave clear that this exit is 'love' as an overcoming of the same Hegelian philosophy when it considers that the individual can reach a self knowledge from its own self-affirmation, and at the same time, it is the overcoming of Raskolnikov within his utilitarian moral.

\footnotetext{
Estudiante de sexto semestre de la Facultad de Filosofía de la Universidad Santo Tomás.
} 


\section{Key words}

Hegel, Dostoievsky, wretched conscience, self-consciousness, self-affirmation

\section{Introducción}

A lo largo de la historia de la filosofía moderna, la consideración de sujeto que nace con Descartes se transforma en una entidad sumamente particular. Su origen, en el racionalista francés, es simplemente la de un sujeto que se conoce a sí mismo como diferente del mundo en el que se encuentra. Es ante todo un sujeto cognoscente, pero el curso del pensamiento de las épocas siguientes determina que esa noción de sujeto se universalice hasta considerar que es Dios mismo, como en Spinoza. Leibniz y los empiristas combatieron fuertemente esa noción de un sujeto que se absolutiza, hasta llegar a Hume quien considera que el sujeto como tal no posee una existencia substancial, sino que es la hilación de toda una serie de impresiones e ideas. Kant asume la herencia racionalista, pero con las advertencias de Hume. Considera el filósofo de Könisgberg que ese sujeto particular y cognoscente que había encontrado Descartes es ahora un sujeto "trascendental", es decir es un sujeto que, sin ser sujeto en particular, es la condición de todo sujeto en general. En términos kantianos hablaríamos de la condición incondicionada. En este punto nacen los idealistas. Fichte, Schelling y Hegel considerarán que ese sujeto trascendental del que hablaba Kant es el absoluto que busca la filosofía.

En Hegel, de quien hablaremos específicamente, encontramos al Espíritu que se conoce por medio de la historia gracias a los individuos y las sociedades, quienes en su caminar desarrollan el proceso histórico de la consecución de la libertad. Tal proceso posee un equivalente epistemológico; en éste encon- tramos una conciencia que conoce la cosa, para luego conocerse a sí misma en una autoconciencia y, de esa manera, llegar al conocimiento de lo absoluto. Todo el conocimiento, desde las ciencias naturales hasta la filosofía, es el camino en que el Espíritu se conoce a sí mismo.

Pero, en esta perspectiva, surge el interrogante de cómo se relaciona el individuo concreto con el espíritu, si se trata sólo de una hipóstasis, o de un medio. Si un hombre desea autoafirmarse, realizarse como individuo, entonces ¿cómo puede pertenecer a la sociedad?, o, dicho de otra manera: ¿cuáles son las condiciones para que los deseos de los individuos puedan ser parte de este conocimiento del espíritu?

Este es el caso de un personaje célebre en la literatura: se trata de Raskolnikov, quien desea la autoafirmación en su sociedad, quien se cree superior y busca superar la sociedad de su tiempo. Es inminente la superación de este hombre en su comunidad limitada, pero ¿hasta qué punto puede hacerlo?, ¿qué consecuencias trae este deseo de individualización?

Este es el tema que deseo desarrollar en mi ensayo; tratar de comprender a Raskolnikov como un ser desesperado que se debate entre su autoafirmación y la eticidad de su sociedad. Para tal fin partiré de la concepción de hombre hegeliana y la de Raskolnikov; de aquí pasaré a analizar el personaje de Raskolnikov en su desesperación confrontándolo con las ideas hegelianas; y concluiré con la paradoja que se le presenta a Raskolnikov, personaje desesperado, y cómo puede ser solucionada. 


\section{Concepción de hombre: Hegel- Raskolnikov}

\author{
¿Qué es lo que más teme el hombre? El \\ dar un nuevo paso.
}

Raskolnikov

Para Hegel, el hombre se presenta entre la inmediatez y la trascendencia, en el gran dilema del infinito y lo finito. "El hombre tiene que hacerse a sí mismo lo que debe ser, tiene que adquirirlo por sí solo (...) hombre es sólo la posibilidad de serlo, de ser racional, de ser libre"2. El individuo es una necesidad de ser, un proceso. En sí mismo contiene la contradicción y es por esta contradicción que está en continuo movimiento entre el negarse y el ser; pasando de ser en sí a ser para sí, a universal.

Papaioannou dice enfáticamente respecto a este punto: "en Hegel el hombre es una contradicción perpetuamente resurgente, que consiste en representar el todo por su concepto y en ser un aspecto de este mismo todo

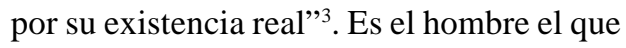
con su capacidad de trabajo transforma el mundo y al mismo tiempo se transforma a sí mismo, en el juego entre el deseo y el traba$\mathrm{jo}^{4}$, parte esencial del desarrollo humano.

Es necesario recordar que en Hegel el individuo como subjetividad tiene muy poca importancia, el individuo real es el pueblo; tanto la historia como los sujetos existen como formas en que el espíritu se idealiza. Desde esta perspectiva, en Hegel encontramos a seres "superiores": los individuos históricos. Estos hombres son los que empujan los cambios porque es en ellos en donde está inserto el fin verdadero del espíritu; "los grandes individuos en la historia universal son, pues, los que aprehenden un contenido universal y hacen de él su fin”, no encuentran su misión en el Estado existente sino en el que debe ser. Estos sujetos son grandes porque pueden conducir a las demás personas $^{6}$ hacia el desarrollo de la libertad.

Frente a esta concepción de hombre se nos presenta el protagonista de Crimen y castigo; podríamos considerar que en toda la obra Raskolnikov se pregunta: “¿quién soy yo?”; es acaso lo que en el principio de la obra se muestra: un ex estudiante que vive en un cuchitril, en una ciudad hostil, y duerme bajo su propia ropa interior sucia; o es, en cambio, lo que puede llegar a ser gracias a sus potencialidades, ser un nuevo hombre, dar el nuevo paso. En el anterior dilema se muestra la concepción de hombre de Raskolnikov, justificada en su ensayo sobre el "crimen"', donde divide a los hombre en ordinarios y extraordinarios: "las primeras [personas] por su condición de ordinarias han de ser obedientes y dóciles y no tienen derecho a in-

G. W. F. Hegel, Lecciones sobre la filosofía de la historia universal, vol. I (Madrid: Altaya. 2000) 62. Kostas Papaioannou, Hegel (Madrid: Editorial Edad, 1975) 60.

4 Podemos ver la importancia que en Hegel tienen la pasión y el deseo de actuar, pues es gracias a este sentimiento que el espíritu en el hombre transgrede los límites y se idealiza. Es interesante a la vez que en "la filosofía de la historia” defina el interés como "un ser en ello, estar en ello", es decir, en el momento en que deposito mi interés en algo en cierta medida me convierto en ese algo; abstraigo lo demás de mí para convertir mi interés en el desarrollo de la existencia. Cf. Hegel, Lecciones..., 81.

5 Hegel, Lecciones..., 92-100.

6 "Por esto el gran hombre ejerce un poder al que se entregan los demás, incluso contradiciendo su voluntad consciente, los demás siguen a este conductor de almas porque sienten que en él está el irresistible poder de su propio espíritu interno”. Hegel, Lecciones..., 92-100.

7 La primera mención de este artículo de Raskolnikov es en el capítulo sexto de la tercera parte; en el crono de la novela, Raskolnikov escribió el artículo unos seis meses antes de que entrara en él la "extraña idea" de matar a la vieja. 
fringir las leyes. En cambio, las extraordinarias tienen derecho a realizar cualquier clase de crimen y a infringir las leyes que les plazca por el mero hecho de ser extraordinarios" ${ }^{\text {. }}$. Podemos ver en Raskolnikov, como en Hegel, que el hombre son sus acciones, su hacer por medio del trabajo.

Igualmente se da una división de hombres entre los que decretan y los que son mandados. Raskolnikov cree en estos individuos que por dar una nueva idea pueden transgredir los límites que les implanta su sociedad con miras a un fin superior; el hombre extraordinario puede derramar sangre (aunque sea sangre inocente). Raskolnikov es aún más crudo que Hegel al considerar que cualquier avance es un crimen: "todos los hombres que desean decir algo nuevo han de ser criminales por propia naturaleza. "El infringir el límite conlleva acabarlo, “devorarlo", en palabras hegelianas, por lo cual sólo es labor de seres capaces de decir algo nuevo, capaces de cargar con el peso de su propio ego.

Hasta aquí podemos encontrar una unión muy cercana entre Hegel y Raskolnikov: los dos consideran al hombre como proceso, ambos creen en seres que sobresalen entre los demás y que por lo mismo pueden transgredir los límites. Hay, sin embargo, una escisión fundamental en lo que se refiere a lo que da este derecho.

Para Hegel, lo que da a un individuo el derecho de traspasar la moralidad de su tiempo es que en él esté el germen de una nueva sociedad; por el contrario, en Raskolnikov este derecho es completamente individual, leja- no a cualquier concepción de sociedad. Raskolnikov es un ser egoísta, y su deseo de transgredir los límites se basa en el deseo de autoafirmación. Un hombre superior es aquel que dentro de sí mismo es mejor que los otros, hasta el límite de considerar sólo personas a estos seres superiores mientras que los ordinarios sólo son una masa "peterburguesa" que se pierde en el insalubre medio ${ }^{9}$.

\section{Individuo- sociedad}

Esta escisión nos lleva a preguntarnos por el individuo en sociedad. En Hegel no se debe creer que el hombre se hace solo, al contrario se hace en la sociedad; aún más correcto sería decir que la sociedad se hace por medio de los hombres. Esto se notaba ya desde sus escritos de juventud: "el espíritu de un pueblo, la historia, la religión el grado de libertad política no pueden considerarse aisladamente; están unidos de manera indisoluble" ${ }^{10}$. Además, "No puedes tú ser mejor que tu tiempo, en el mejor de los casos serás tu tiempo" ${ }^{11}$. Estas sentencias muestran cómo el individuo, como parte del espíritu que se conoce, esta inserto en una sociedad. El mismo Hegel consideraba tanto su filosofía como su vida parte interna del desarrollo de la sociedad, hasta el punto en que cuando una mujer le felicitó por su trabajo, él respondió: "lo que en mi trabajo hay de mí es mentira" ${ }^{12}$. El valor de los individuos descansa en que sean conformes al espíritu del pueblo.

Se ve al individuo como parte de un todo que se esta conociendo y del cual no puede

\footnotetext{
Fiodor Dostoievski, Crimen y castigo (Bogotá: Oveja Negra, 1999) 298.

Cf. Dostoievski, Crimen ..., 270.

G. W. F. Hegel, “Teología juvenil”, Hegel, de Papaioannou, op.cit.

G. W. F. Hegel, “Documentos”, Hegel, de Papaioannou, op.cit., 18.

12 Cf. Ernst Bloch, Sujeto y objeto: El pensamiento de Hegel (México: Fondo de Cultura Económica, 1983) cap. I.
} 
escapar, sino que debe mediar con él si desea encontrar su verdad. "el fin universal reside en los fines particulares y se cumple mediante estos”13, el individuo por sí sólo no puede adquirir conciencia ${ }^{14}$, es por medio del espíritu objetivo (el espíritu del pueblo) que logra mediar con el absoluto y conocerse. Hasta las pasiones de los hombres históricos, sus deseos personales, concuerdan realmente con los fines universales. Un Napoleón no actuó por sí mismo ni se convirtió en “el espíritu universal” por su afirmación como individuo, sino porque sus deseos individuales eran conformes al deseo del espíritu.

Esta concepción es completamente contraria a la que nos da Dostoievski en su personaje. San Petersburgo es el signo de una sociedad acabada, sucumbida en el desasosiego, "Difícil sería encontrar otro lugar donde el alma humana esté sujeta a influencias tan sombrías, contradictorias y raras como Petersburgo" ${ }^{15}$. Desde las primeras hojas del libro nos embargamos con el tufo proveniente de la degeneración; encontramos a Marmeladov, un ebrio que vive de la prostitución de su hija, a Ivanovna, una vieja usurera que golpea a su hermana. El sentimiento de Raskolnikov frente a su sociedad es de irremediable asco. Son innumerables las veces que se hace aclaración de este sentimiento del personaje frente a lo que sucede alrededor; Raskolnikov se siente diferente a los demás, por lo cual trata de afirmarse frente a su sociedad, no de seguirla.
Pero al mismo tiempo, su alma es rusa: "Los rusos son de alma muy vasta como lo es su tierra y poseen una extraordinaria inclinación hacia lo fantástico, lo desordenado; pero, es una desgracia tener el alma vasta sin ser a la vez genial”16. Es el espíritu romántico de Raskolnikov, un personaje que se debate entre la autoafirmación del orgullo y una solidaridad con el desvalido. Un alma grande que desea ser genial cueste lo que cueste, y que como ruso vive su propia idea y desea cumplirla en su vida ${ }^{17}$.

Al igual, trata de autoafirmarse en la ayuda que proporciona a los demás. Podríamos recordar cuando habla respecto a su anterior prometida y afirma que si hubiera sido coja o jorobada la hubiera querido más; o el sentimiento de infinita alegría al darse cuenta de que está bañado en sangre del hombre al que trató de auxiliar. El desarrollo en sociedad de Raskolnikov se basa en su deseo de hacerse reconocer, de autoafirmarse como individuo.

\section{Autoafirmación y eticidad: acaecimiento de la desesperación}

\subsection{Moralidad y eticidad}

En Hegel se hace distinción entre moralidad y eticidad-diferencia que nos será necesaria para entender a Raskolnikov como ser desesperado. Se entiende moralidad como los estatutos subjetivos, que obedece al deber por

13 Hegel, Lecciones..., 85.

14 Recordemos que es esta la crítica más tajante de Hegel a Fichte respecto al subjetivismo. Para Hegel el individuo necesita el reconocimiento de los otros para reconocerse a sí mismo, de lo contrario al encerrarse en sí mismo no podrá salir de "su noche oscura”.

15 Dostoievski, Crimen ..., 491.

16 Dostoievski, Crimen ..., 516.

17 Joseph Frank, Los años milagrosos, vol. II de Dostoievski (México: Fondo de Cultura Económica, 1998). 
la voluntad; y eticidad es el conjunto de normas de la sociedad; esto explica que la moralidad se encuentre en la Fenomenología en el capitulo de la razón (aún subjetiva) y la eticidad en cambio en el del espíritu (parte del absoluto); "la eticidad es el espíritu en su verdad inmediata" 18 .

Desde esta óptica debemos analizar la realización de la idea de Raskolnikov: él como individuo se ve "indicado" para romper barreras y transgredir límites, se siente con la necesidad de matar a la "vieja usurera" como parte de su primer paso (esta idea se ve reforzada por la sensación de predestinación que siente Rodia en la taberna al escuchar a dos personas discutir sobre el asesinar a esa mujer como un acto altruista, cuando él mismo, Raskolnikov, acababa de pensarlo). Su moral utilitaria indica que su actuar está conforme a una ley superior y que es su derecho y hasta su deber deshacerse de sus sentimientos piadosos y “moralistas débiles" y acertar el golpe final.

Pero frente a esta idea, a su "monomanía", se enfrenta la eticidad, el "no matarás", polo opuesto a su idea, que le exige como deber no seguir sus supuestos; "la conciencia" que expresamente se trata en Crimen y castigo es esta eticidad que como un martillo retumba en la mente de Raskolnikov. Es la sensación religiosa, el deber frente al espíritu objetivo y frente a parte de sí mismo.

Entonces, Raskolnikov se encuentra entre su ley interior de "razón y poder" que él mismo se ha forjado, y el reprimir su ego al entregarse a la vida normal de su sociedad; es este debatirse lo que muestra la primera semilla de desesperación: el "ensayo", su hipocon- dría, nos hará por primera vez vislumbrar el desgarramiento interior del personaje; es el saber si puede o no transgredir el mundo de la eticidad por su individualidad, o si en cambio es un ser débil. En torno a Duniecka, dice: "se vende para otro, jse vende por un ser querido, divinizado!, se vende por el hermano, por la madre (...) en casos semejantes ahogamos nuestro sentido moral. Llevamos al rastro la libertad, el sosiego hasta la conciencia, todo"19. Encontramos en esto un punto aún más interesante: ¿por qué podemos pasar la eticidad? Por el amor a los demás, como en el caso de Duniecka y Sofía, o por el simple ego, como es el caso de Smirnilaivdov.

\subsection{La vida: dialéctica del reconocimiento}

La quimera de Raskolnikov es acabar con lo que representa San Petersburgo y, al mismo tiempo, imponerse como ser individual, tomar la vida, agarrarla y hacerla su vida. “Todo está en manos del hombre y por cobardía deja que se le escape”20 y en este impulso, el deseo de autoafirmación se denota en el atreverse: "el que se atreve a más es el que más razón tiene”, es decir, por medio del matar a la vieja, que es el ícono de la vileza y lo ruin, llegar a una afirmación como ser superior, y conocerse en esto, saberse como "hombre extraordinario". Podríamos explicar este paso en términos hegelianos, en el desarrollo de la vida como dialéctica de reconocimiento, desde el momento en que la conciencia se convierte en autoconciencia, pues es esta autoconciencia la que realmente desea Raskolnikov al empuñar el hacha y estrellarla en la cabeza de Aliona Ivanovna.

\footnotetext{
18 G. W. F. Hegel, Fenomenología del espíritu (México: Fondo de Cultura Económica, 1966) 266.

19 Dostoievski, Crimen ..., 46.

20 Dostoievski, Crimen ..., 6.
} 
Me refiero a que en Hegel el yo se conoce por medio del tú ("una autoconciencia sólo se conoce por otra autoconciencia") ${ }^{21}$, pero este conocimiento es a la vez una confrontación entre las dos autoconciencias por el reconocimiento de la otra, es una lucha en donde se arriesga la vida, y cada una se impone frente a la otra en su búsqueda del ser para sí; y es mediante este mostrarse que la conciencia encuentra su autoconciencia.

Ahora demos un salto a la conciencia individual de Raskolnikov; él como individuo quiere autoafirmarse, desea saber quién es, y sólo puede cumplir este propósito en cuanto se muestre a los demás y en cuanto, como ser social, actué y trasforme su realidad. A Raskolnikov se le presenta la inmediata verdad de que son pocas las oportunidades de surgir; el deseo de reconocimiento es su razón para vivir: "La vida se me da una sola vez y nunca volveré a tenerla: también yo quiero vivir y, si no, mejor es no vivir"22. "O [matar a la vieja o] bien renunciar a la vida aceptar el destino sumisamente tal como es, de una vez para siempre, ahogarlo todo en mí, renunciar al derecho de obrar, de vivir y de amar"23.

Un juego de contrarios perturbador se nos presenta en esta concepción de vida completamente ligada a la autoafirmación, ya que Raskolnikov, o logra comprobarse que es un ser "extraordinario" y puede hacer su vida, o de lo contrario es la vida la que lo hace a él; se hace inminente la necesidad de arriesgar esta vida, en el estilo hegeliano, enfrentarse a las demás conciencias y lograr el reconocimiento.

\subsection{Desesperación}

Una muerte y a cambio cien vidas; ;si es cuestión de aritmética! ${ }^{24}$.

Para Hegel una conciencia fuera de la sociedad se convierte en una conciencia desgraciada, desventurada: "la conciencia desgraciada es la conciencia de sí en cuanto ser desdoblado que sólo se contradice”25. Desde este concepto puro como la conciencia que se experimenta a sí misma dividida contra sí, en pugna entre su infinitud y su finitud, tratemos de aplicarlo a Raskolnikov.

Es decir, Raskolnikov es un ser desesperado en su intento de ser un "hombre extraordinario”, su desesperación se basa en la contradicción de su idea y los hechos al cumplirlo; anteriormente decíamos que desea autoafirmarse y traspasar los límites de la eticidad, pero él mismo es parte de esta eticidad. Esto se nos hace palpable ya desde “el ensayo” en el primer capítulo: “Oh, Dios, qué repugnante es todo esto (...) ¿cómo pudo ocurrírseme una cosa tan atroz?”26. Pero su idea le indica que el partir una cabeza de un hachazo no es un crimen, pues tiene el "derecho moral” de cambiar la naturaleza. La desesperación radica en la discrepancia entre la idea abstracta y la realidad humana concreta.

Así, Raskolnikov pasa en toda la obra de un extremo a otro. Es un hombre que vivía por una idea y que, al hacerla vida, la ha acabado, que no logra conquistar su "moral ordinaria” y convertirse en un ser superior. Pero, a la vez, no logra darse cuenta de que come-

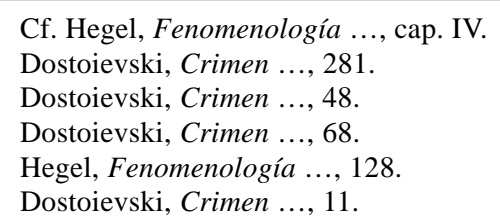


tió un crimen: “¡No es un ser humano lo que yo he asesinado, sino un principio! He asesinado un principio, pero no he sabido saltar por encima de los obstáculos y me he quedado en esta parte (...) ¡sólo he sabido matar!”27. Raskolnikov no se arrepiente de haber asesinado, sino de no haber sido el hombre. Su conciencia desgraciada se debate entre su autoafirmación y la eticidad, sin optar por ninguno de las dos ${ }^{28}$.

Esta sensación interna hace que desaparezca cualquier unión con los demás (Raskolnikov inevitablemente se encuentra sólo en su desesperación) y que, al mismo tiempo, se vea impelido a actuar, de manera casi inconsciente, acciones “desesperadas": pasa del odio a sentimientos de compasión -podemos recordar el momento en que deja todo su dinero a la familia Marmeladov y apenas al salir a la calle se arrepiente de haberlo hecho-, no sabe por qué actúa -por ejemplo, cuando va a la casa de Razumijin y al llegar se da cuenta que no sabe para qué ha ido. Es esta debilidad humana que no estaba en sus proyectos lo que aún lo hace desesperar más.

Esta conciencia se debate también respecto a los motivos por los cuales mató, entre el altruismo "de una muerte y a cambio cien vidas” y él mismo, por probar su ego: “necesitaba saber si yo era un piojo, como los demás, o una persona. ¿Podría saltar los obstáculos o no? Era una criatura temerosa o tenía derecho...”29; desde Hegel, Raskolnikov no tiene fundamento para traspasar los límites de la sociedad, ya que no actuó por esta sociedad. Su crimen es una autoafirmación. Y tampoco encuentra este fundamento en sí mismo: él no es un "hombre extraordinario", es débil, y como débil, ordinario. "Quería matar sin que fuera un caso de conciencia, ¡quería matar para mí, para mí solo! (...) no tenía derecho a hacer lo que hice porque soy un piojo exactamente como los demás"30.

Frente a esto, es necesario actuar nuevamente para salir de la desesperación. Retumba la expresión de Porfiri Petrovich: "ha ideado un teoría y se avergüenza de haber fracasado, de no haber resultado muy original. ¿Tiembla usted ante la idea de dar el gran paso que le espera? Temblar ahora es una vergüenza. Después del paso que ha dado, no tiene más remedio que ser valiente" ${ }^{31}$. Pero Raskolnikov tiembla por lo hecho y a la vez por el temblor mismo, es él un ser desesperado y debe dar un nuevo paso para salir de su propia encrucijada, debe "ser valiente".

\section{Conclusión: ¿qué puede hacer una conciencia desesperada?}

Esta desesperación lleva a la siguiente paradoja: o bien Raskolnikov con su autoafirmación llega a una autoconciencia de tipo particular, y entonces el sistema hegeliano presenta una ruptura; o bien esta autoafirmación de Raskolnikov no puede llegar a la autoconciencia, y es solamente un paso en el desarrollo del espíritu.

Ahora bien, si la autoafirmación es autoconciencia, tendríamos que considerar, por fuera del pensamiento de Hegel, la posibilidad de que el individuo llegue a tener contacto con la conciencia absoluta sin necesidad de la participación del espíritu objetivo. De optar por este lado de la paradoja, llegaríamos a las mismas consideraciones que

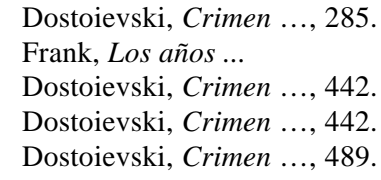


Kierkegaard hace respecto al sistema hegeliano, a saber, que debe existir una relación del particular con el absoluto sin necesidad de la mediación de lo general. Aunque Kierkegaard nos habla en términos religiosos, expresamente con el caso de Abraham, podemos asumir la forma de los argumentos del pensador danés. De esta manera, resultaría que la relación con el absoluto se establecería de manera particular, puesto que la autoafirmación bastaría para llegar a la autoconciencia, prescindiendo de la mediación que Hegel considera necesaria. Cabría preguntarnos si el absoluto es el mismo del que Hegel nos habla, a lo que responderemos afirmativamente en la medida en que es a través de la conciencia individual que el absoluto llega a una autoconciencia. Expresando esto en términos más sencillos, se trata de eliminar la mediación de lo general (espíritu del pueblo) para que por medio de la autoafirmación se llegue a un contacto con la autoconciencia absoluta.

Veamos unas citas de la obra al respecto:

Si hubiera asesinado sólo por hambre ahora estaría feliz (...) yo quería ser un Napoleón y por eso maté. Maté... siguiendo el ejemplo de autoridad (...) al fin sólo he dado muerte a un piojo, a un piojo inútil, asqueroso, pernicioso ${ }^{32}$.

Una sensación tenebrosa de soledad y aislamiento, infinitos y dolorosos, se manifestó de pronto con toda conciencia en su alma, ya no podría dirigirse a las personas. Tenía una rara impresión, como si en aquel momento hubiera cortado con unas tijeras cuantos lazos po- dían unirle con los hombres y con las $\operatorname{cosas}^{33}$.

El sufrimiento y el dolor son siempre necesarios para la conciencia de altos vuelos y para el corazón profundo. A mi modo de ver, los hombres verdaderamente grandes han de experimentar en este mundo una pena inmensa ${ }^{34}$.

¿Mi crimen? ¿qué crimen? ¿el que haya matado a un piojo nocivo, asqueroso, a una vieja usurera que no hacía falta a nadie? Por matarla habían de perdonarme la mitad de los pecados (...) ¿ es eso un crimen? No pienso en él, ni pienso lavarlo. ¿Por qué me repiten todos, de todas partes: "tu crimen, tu crimen"? sólo ahora veo con claridad cuán absurda ha sido mi cobardía, ahora que ya me he decidido a pasar por esta innecesaria vergüenza. Si me decido es sólo por vileza e incapacidad ${ }^{35}$.

Desde esta postura podríamos afirmar que Raskolnikov, prescindiendo del espíritu objetivo, puede llegar a considerarse como una autoconciencia lograda por el largo camino de la desesperación. Raskolnikov mata, se desespera y actúa en un encuentro consigo mismo, y desde aquí logra saberse a sí mismo como un "para sí", tomando como cosa todo lo demás.

Si tomamos el segundo miembro de la paradoja, en el que la autoafirmación no es autoconciencia, la desesperación de Raskolnikov no sería más que un paso de la dialéctica del espíritu. Se diría que es el primero de los pasos de la dialéctica, afirma-

\footnotetext{
Dostoievski, Crimen ..., 439.

Dostoievski, Crimen ..., 120.

Dostoievski, Crimen ..., 275.

55 Dostoievski, Crimen ..., 543.
} 
ción a la que correspondería la negación en la figura de Sonia, ${ }^{36}$ que con sus actitudes y pensamientos persuade a Raskolnikov de aceptar la mediación y volver a pertenecer a lo general, lo que resultaría ser la síntesis o finalización del proceso dialéctico del espíritu en la conciencia de Raskolnikov. En otros términos, esta parte de la paradoja señalaría que en el caso de Raskolnikov sigue vigente, completamente, el sistema hegeliano y que todo el proceso no es otro que el del retorno de la conciencia desgarrada al sistema.

Tengamos en cuenta las siguientes citas:

¿Maté a la vieja? ¡Me mate a mí mismo, no a ella! ${ }^{37}$.

El que la tiene (conciencia) a sufrir se ha dicho, si reconoce el error es su castigo, además del presidio $^{38}$.

La desesperación, el sufrimiento, se nos presentaría como un paso en el desarrollo del espíritu, que primero se autoafirma, pero luego, al ver que aún es incompleto, se une a la sociedad por medio de la mediación, que en este caso es Sonia, como completa antítesis del ego superior de Raskolnikov, como la mujer que se ha dado toda por los demás en vez de que los demás den todo por ella.

Pero ninguna de las dos posturas lleva a encontrar la salida de Raskolnikov. No podemos considerar que este personaje, tan humano, pueda vivir fuera de la sociedad, pero creer que el sistema hegeliano, en su integridad, es verídico como explicación del mundo, sería caer en un error, pues lamentablemente Hegel no explica al individuo como existencia particular.
Entonces, en esta contradicción, el camino por el que se debe optar es una superación de los dos, es encontrar la síntesis en la paradoja, es decir: Raskolnikov como individuo puede llegar a autoconocerse desde su autoafirmación. Pero, a la vez, esta autoafirmación debe estar mediada por el reconocimiento de la autoafirmación del otro. Podemos ver el eco de la moral kantiana de tratar a los demás como fin y no como medio; Raskolnikov cae en desesperación al no poder unir su ego a la necesaria relación con las demás personas, hasta que encuentra a Sonia. Pero, a la vez, no se pierde en el espíritu objetivo junto a Sonia, es una existencia concreta.

Se mató a sí mismo espiritualmente al matar a la vieja, al no reconocerla como fin, como existencia individual, y resurge por medio del amor; pues, como también lo decía Hegel, sólo en el amor se reconoce al otro como otro $^{39}$. Pero, en contra de Hegel, no lo consideramos fracasado por no superar la esfera de lo individual; antes bien, es esta esfera de lo individual lo que proclamamos, es en ella en donde se resurge con el otro.

El temblor febril que la agitaba aún no había mitigado. Hacía rato que el cabo de la vela se estaba consumando en el candelabro torcido, iluminando apenas, en aquella habitación sórdida, a un asesino y a una mujer descarriada, extrañamente reunidos leyendo el libro eterno ${ }^{40}$.

El amor en la entrega al otro y, a la vez, la autoafirmación como individualidad, es el único camino que Raskolnikov puede tomar para salir de su desesperación: "los hizo renacer el amor; el corazón de uno contenía

\footnotetext{
Edward Hallet considera a Sonia como la autosumisión, en contra de Raskolnikov que es la autoafirmación.

7 Dostoievski, Crimen ..., 443.

Dostoievski, Crimen ..., 274.

39 Cf. Hegel, Fenomenología ..., 130ss.

40 Dostoievski, Crimen ..., 347.
} 
fuentes inagotables de vida para el corazón del otro" ${ }^{41}$; es ésta la solución de la paradoja: una inserción en la comunidad desde la autoafirmación y el autoconocimiento en el amor. Aquí se termina Hegel en considerar innecesarias las individualidades y se termina Raskolnikov en considerar como objetos a los seres que están a su alrededor. Aquí, "la dialéctica había cedido el lugar a la vida y la conciencia debía de elaborar algo completamente distinto".

\section{Bibliografía}

Bloch, Ernst. Sujeto y objeto: El pensamiento de Hegel. México: Fondo de Cultura Económica, 1983.

Camargo, José. El conocimiento como parte del saber absoluto en la Fenomenología del espíritu de G.W.F. Hegel. Bogotá: Universidad Javeriana, 1971.

Dostoievski, Fiodor. Crimen y castigo. Bogotá: Oveja Negra, 2000.

Frank, Joseph. Los años milagrosos. Vol. II de Dostoievski. México: Fondo de Cultura Económica,1998.
Hallett, Edward. Dostoievski (1821-1881). Barcelona: Caia, 1973.

Hegel, G. W. F. Lecciones sobre la filosofía de historia universal. Vol. I. Barcelona: Altaya, 1994.

- Fenomenología del espíritu. México: Fondo de Cultura Económica, 1966.

—. Escritos de juventud. México: Fondo de Cultura Económica, 1978.

Kojeve, Alexandre. La dialéctica del amo y el esclavo. Buenos Aires: Editorial La Pleyade, 1977.

Labarriere, Pierre- Jean. La Fenomenología del espíritu de Hegel. México: Fondo de Cultura Económica, 1985.

Marcuse, Herbert. Razón y revolución. Buenos Aires: Altaya, 1995.

Papaioannou, Kostas. Hegel. Madrid: Editorial Edad, 1975.

41 Dostoievski, Crimen ..., 575. 